Images in Medicine

\title{
PNEUMOCEPHALUS DURING CABERGOLINE TREATMENT OF AN INVASIVE MACROPROLACTINOMA
}

\author{
F. Jouret, V. Col
}

\section{LEGEND}

A 43-year-old male trisomic patient was referred for acute left headache and progressive homolateral mydriasis and ptosis. Computed tomography and T2-magnetic resonance imaging demonstrated a $4 \mathrm{~cm}$ invasive pituitary adenoma (Panels $A$ and $C$, respectively). Blood analyses revealed hyperprolactinemia $(5460 \mathrm{ng} / \mathrm{ml}$, normal values $<15 \mathrm{ng} / \mathrm{ml}$ ) and severe gonadotrophic insufficiency. Treatment was classically initiated with a dopamine agonist (cabergoline, $0.5 \mathrm{mg}$ per week) and resulted in a rapid improvement of neurological symptoms and prolactinemia $(2247 \mathrm{ng} / \mathrm{ml})(1)$. Three weeks later, the patient complained of headache, nausea and dizziness. Similar radiological investigations showed a significant shrinkage of macroprolactinoma, as well as pneumocephalus (Panels B and D, arrowheads). Cabergoline treatment was continued and transnasal surgery performed to seal sinus breach of the sella turcica. Pneumocephalus represents a severe complication of dopamine agonist treatment of invasive prolactinoma (2). Drug-induced tumour shrinkage unmasks the erosion of the sella floor, thereby allowing CSF-leakage and/or pneumocephalus (3).

Division of Endocrinology,

Clinique Saint-Pierre,

Ottignies, Belgium

Address for Correspondence:

Vincent Col, MD

Division of Endocrinology, Clinique Saint-Pierre

Avenue Reine Fabiola, 9

B-1340 Ottignies, Belgium

Phone: +32 10437797

Fax: +32 10414370

vi.col@clinique-saint-pierre.be

\section{REFERENCES}

1. Molitch ME, Thorner MO, Wilson C. Management of prolactinomas. J Clin Endocrinol Metab 1997; 82: 996-1000.

2. Bevan JS, Webster J, Burke CW, Scanlon MF. Dopamine agonists and pituitary tumor shrinkage. Endocr Rev 1992; 13: 220-240.

3. Leong KS, Foy PM, Swift AC, Atkin SL, Hadden DR, MacFarlane IA. CSF rhinorrhoea following treatment with dopamine agonists for massive invasive prolactinomas. Clin Endocrinol 2000; 52: $43-49$
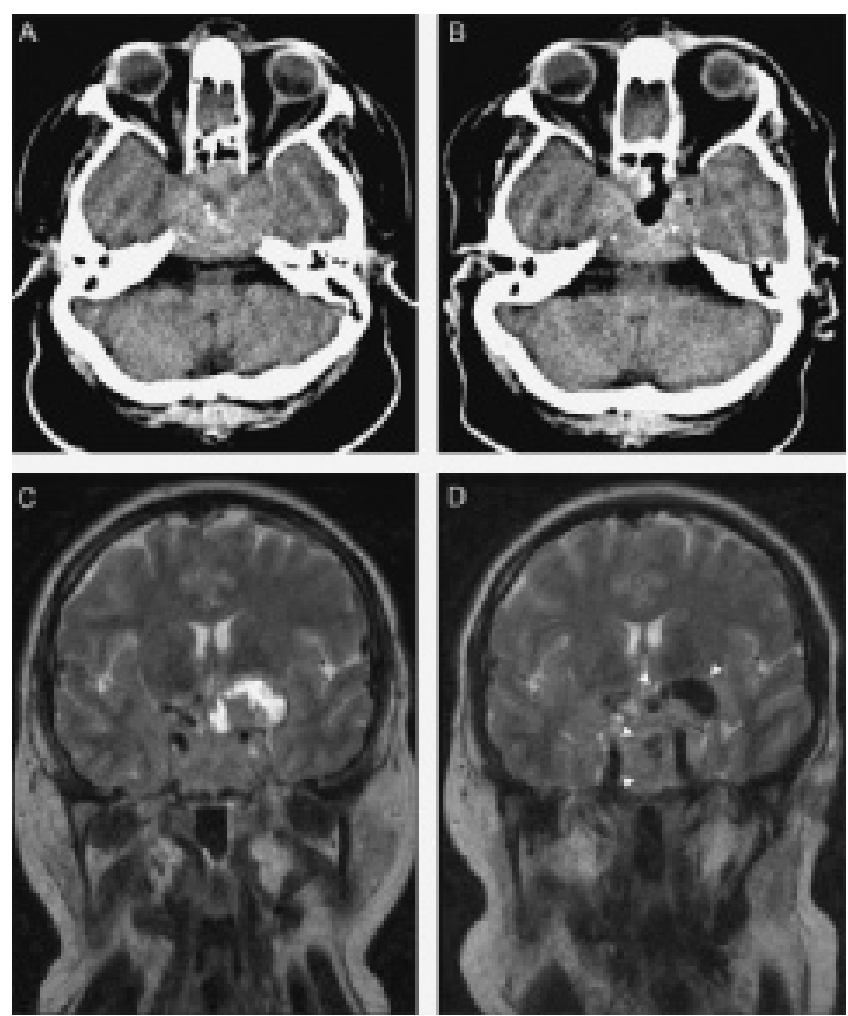